\title{
LA SENTENCIA CONSTITUCIONAL
}

\author{
POR \\ ANGEL GARRORENA MORALES \\ Profesor Agregado de Derecho Político \\ Universidad de Murcia

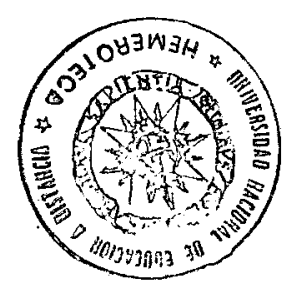

\section{SUMARIO}

I. Planteamiento.-II. Princtrio de congruencia.-III. Principio de motrvación.-IV. Principio de colegialidad,-V. Principio de eficacia. VI. ConClusión.

\section{PLANTEAMIENTO}

La reaparición en nuestro país, tras la compleja experiencia de la II República, de una jurisdicción constitucional por obra y gracia del título IX de nuestra reciente Constitución de 1978, ha reactualizado entre nosotros el interés por un tema cuya importancia sería difícil exagerar: la sentencia de los Tribunales Constitucionales.

No me parece, sin embargo, pese a lo que esa importancia pudiera hacer suponer, que ésta sea una cuestión habitualmente bien tratada. Las dificultades al respecto -dificultades que, como veremos de inmediato, este trabajo tampoco va a tener la pretensión de superar de modo pleno- me parece que pueden haber provenido de no encarar adecuadamente la entidad poliédrica del tema, esto es, de no contornear suficientemente el objeto hasta tomar conciencia de su realidad plural. Cierto que la sentencia constitucional es -ante todo- acto procesal, decisión de un colegio de jueces que pone término a un proceso... Pero además es también, y en un grado eminente, actividad dirigida a la interpretación e integración creadora del Derecho..., a esa interpretación creadora de la que el profesor Paul A. Freund, de la Universidad de Harward, dijera, con acertada expresividad, que implica siempre una inevitable tensión entre la vitalidad y la técnica..., entre la pasión y la simple pericia. $Y$ desde luego, en tercer lugar, la sentencia constitucional es todavía algo más: es, indefectiblemente, decisión política..., acto de un poder en dialéctica con los demás poderes del Estado.

En la primera de estas dimensiones -y ello es tan coherente como correcto- suelen agotar su visión los procesalistas, tan interesados hoy por poner su pie en esta zona. La segunda de tales perspectivas interesa habitualmente, y mucho, a los cultivadores de la hermenéutica jurídica; baste recordar que los esfuerzos de Martin Kriele, Friedrich Müller o Wolfgang. Fikentscher por replantear de raíz toda la teoría de la interpretación tienen cabalmente su incentivo más originario, su mejor estímulo, en la jurisprudencia producida 
por el Tribunal Constitucional Federal Alemán de Karlsruhe. Los constitucionalistas, en fin, integran a su vez en el análisis esa tercera y fundamentalísima dimensión política, politológica, que es la esencia - la auténtica almendradel tema. Pero, a poco que se medite, se observará que tan parciales puntos de vista, precisamente por serlo, lo único que hacen es dejar oculta, prácticamente desatendida y traicionada, la efectiva condición de la sentencia constitucional, aquella que debe hacerla aparecer como lo que verdaderamente es: como una categoría triédrica..., como un tríptico de ninguna de cuyas hojas o perspectivas es lícito prescindir.

Venidos a este lugar, entiendo y justifico a quien crea que semejante punto de partida me acaba comprometiendo a mucho: a tanto como a asumir frontalmente esa perspectiva integradora que aquí parece reclamarse. Sin embargo, y sin por ello dejar de considerarme prendido en ese compromiso, como vía media entre lo elevado del reto y las inevitables limitaciones que se imponen a este trabajo, espero que se me permita aceptar tal envite interpretándolo «a la baja», esto es, reduciendo algo sus exigencias. Ello quiere decir que no creo viable fundir plenamente en esta oportunidad esos tres puntos de vista, pero sí me parece en cambio posible, conforme a una estrategia menor aunque no por ello menos rentable, optar por una de esas dimensiones, intentando después que quede constantemente trascendida - transformada en su entidad y elevada en su condición - por los datos provinientes de las otras dos perspectivas ${ }^{1}$.

Sea, pues - dada la cualidad del tema-, la dimensión procesal la que quede aquí primada, convertida en hilo conductor y ordenador de su tratamiento, y sirvan los materiales de las otras dos dimensiones para que la sentencia constitucional aparezca entre nosotros como algo muy distinto de lo que acabaría siendo en una perspectiva friamente procesalista. Por supuesto, no se trata de traer aquí íntegramente el tema de la interpretación constitucional, que tiene su autonomía y su entidad diferenciadas; pero cuando hablemos de «concreción» como disciplina de la discrecionalidad del legislador, o cuando rocemos el tema de las sentencias interpretativas, o cuando, en fin, pasemos sobre ciertas técnicas de determinación de los vicios de inconstitucionalidad estaremos hablando implícita, pero inequívocamente, de «interpretación». $Y$ espero que con mucha mayor frecuencia sea notorio que en ningún momento dejamos de hablar de la sentencia como acto de poder.

1 Este trabajo reproduce íntegra y casi textualmente el original elaborado para el tercer ejercicio de unas oposiciones a agregadurías celebradas en el primer trimestre del curso 1980-81. Puede que ello explique muchas de sus limitaciones más llamativas; entre otras, la ausencia de un aparato bibliográfico a pie de página, su cierta oralidad y su provisionalidad inevitable. Tal vez explique también la inviabilidad, a que en el texto se alude, de intentar ese planteamiento omnicomprensivo y más ambicioso que, sin duda, el tema merece: el material recogido conforme a esta intención inicial probó no caber en las estrechas lindes -incluso de tiempo de exposición - que este tipo de ejercicios impone. Quede, pues, dicho planteamiento para otra oportunidad menos costreñida de pies forzados y de imperativos académicos; quede también para una consideración más reposada, de cuya necesidad soy el primero en ser consciente. Es precisamente el convencimiento de que esa mayor maduración requiere tiempo y meditaciones pausadas el que me ha animado a ceder a las solicitudes de la dirección de esta Revista, solicitudes que me apresuro a agradecer, para publicar estas páginas en su estado actual. 
Ciñendo, pues, ya el tema a un esquema presumiblemente eficaz, creo que la sentencia constitucional podría ser perfectamente explicada en la convergencia de cuatro principios fundamentales: el de congruencia, el de motivación, el de decisión colegial y el de eficacia. Principios todos ellos cuyos quiebros - cuya asimetría con lo que serían tales presupuestos en el proceso ordinarioprueban que las claves de fondo del tema que tenemos entre las manos poseen una entidad diferencial netamente política.

\section{PRINCIPIO DE CONGRUENCIA}

La constatación de esa aludida especificidad, que tan de cerca nos toca a los constitucionalistas, nos sale al paso ya desde el momento mismo en que encaramos el primero de tales principios.

Sobre el papel, en pura y muy correcta teoría, sería difícil negar que el juez constitucional, como cualquier otro juez; está sometido a los imperativos del principio de congruencia: también las sentencias de los Tribunales Constitu. cionales deben ser «congruentes», esto es, deben mantener y respetar la más estricta correspondencia entre «demanda» y «pronunciamiento», entre lo que se solicita y aquello que se resuelve (sententia debet esse conformis libello es la formulación aforística más clásica del principio que comentamos), no fallando ni ultra petitum o más allá de lo pedido, ni extra petitum o cosa distinta de lo pedido, ni con otro apoyo que no sea el de la causa petendi, es decir, el de aquellos fundamentos en los que la demanda basó su solicitud.

No constituyen quiebras de esta exigencia así impuesta a las sentencias de los Tribunales Constitucionales aquellas cláusulas -habituales, por otra parte, en toda norma reguladora de dicha jurisdicción- que (como la del artículo 27 de la Ley italiana núm. 87 de 1953, según la cual la Corte «dichiara, altresì, quali sonn le altre disposizioni legislative, la cui illegittimitá deriva come conseguenza della decisione adottata») autorizan al Tribunal a extender el pronunciamiento a otras disposiciones no impugnadas en la demanda, pero cuya inconstitucionalidad se deduce limpiamente como consecuencia o prolongación de la inconstitucionalidad de las que sí se impugnaron. Cierto que la sentencia número 88/1962 de la Corte costituzionale italiana ha pretendido introducir en Italia una interpretación relativamente abusiva de dicho precepto; cierto también que parte de la doctrina (Mortati, con la oposición de Virga) vino en su momento en apoyo de esa jurisprudencia hablando de una «retracción del principio de congruencia» en favor de las exigencias del «principio de economía de los juicios», esto es, en razón de la conveniencia de ahorrar pronunciamientos posteriores, con su ineludible coste procesal, cuando todas aquellas inconstitucionalidades, hayan sido denunciadas o no, aparezcan al juez como manifiestas y evidentes y puedan ser solventadas en una decisión única. Pero más acá de tales excesos está claro que lo que tal tipo de cláusulas ampara es una «extensión de la cosa juzgada a normas conexas», es decir, devenidas carentes de sentido tras la anulación de la anterior, conforme a un esquema simétrico a lo que es la «extensión de la cosa juzgada a terceros» que opera en el proceso común. Algo, a fin de cuentas, que no viene a suponer 
—como no supone en este segundo ámbito— la más mínima debilitación del principio de congruencia.

La única derogación de tal principio que efectivamente debe admitirse aquí afectaría a la causa petendi —nunca al contenido y extensión del petitum - y estaría justificada, como ocurre en los procesos penal y contenciosoadministrativo, en el «interés público» que la resolución del proceso constitucional comporta. El juez constitucional, conforme a ello, puede fundamentar su fallo sobre motivaciones diferentes de las alegadas en el petitum, esto es, puede sustraerse a la causa petendi (apreciar incompetencia del legislador donde se alegó violación material de un precepto constitucional, considerar que es otro el precepto conculcado, etc.), pero no puede separarse del contenido y de las fronteras de la solicitud planteada por la demanda.

Esta es la teoría. Sin embargo, el problema no acaba, ni mucho menos, con su clarificación dogmática. Porque, aunque normalmente esa congruencia se dé en la sentencia constitucional, ello no impide detectar una cierta propensión de los Tribunales Constitucionales a fallar extra petitum, con lo que ello supone de exceso más allá de su neta condición judicial, constreñida a depender de una instancia y, por tanto, de peligrosa pretensión de modificar expansivamente su posición como poder.

Ejemplo paradigmático de pronunciamiento extra petitum es la sentencia del Tribunal Constitucional Federal Alemán de 5 de noviembre de 1975, referida a las retribuciones de los parlamentarios. El recurso, planteado por un antiguo diputado del Parlamento sarrés, impugnaba la Ley del Sarre de 22 de junio de 1973. Por supuesto, impugnaba no todo su articulado ni siquiera la disposición según la cual tanto los funcionarios como los cuadros de empresas públicas que devienen parlamentarios pueden retener -aparte de su indemnización como tales- un 60 por 100 de su retribución anterior, sino escuetamente el artículo según el cual, en detrimento del principio de igualdad, ese 60 por 100 estaba sujeto a un cierto techo en el caso de los empleados de empresas públicas y no en el de los funcionarios. La sentencia, sin embargo (con el voto disidente del juez Seuffert y sometida a duros comentarios de la doctrina como el que le dedicara el profesor Menger en 1976 en el Verwaltungsarcbiv), tomó apoyo en tan escaso petitum, planteado además como recurso directo y ni siquiera en vía de control abstracto de normas, para -eso sí, con un edificante criterio de fondo que le valió una acogida popular espléndida - revisar de abajo a arriba el articulado de la ley, declarar inconstitucionales un buen número de preceptos no impugnados, como el que establecía la inmunidad fiscal de los parlamentarios, ordenar además al legislador del Sarre el replanteamiento total del sistema de remuneraciones percibibles por los diputados e incluso indicar incidentalmente la conveniencia de modificar en el mismo sentido los privilegios económicos de los ministros.

$\mathrm{Y}$, sin necesidad de apelar a casos concretos, dejaría en el aire una pregunta que me parece absolutamente pertinente: ¿Es que la mecánica típica de esa nada inusual especie de sentencias constitucionales que, con denominación italiana, llamamos interpretative di rigetto (en las que se demanda la confirmación de la no constitucionalidad de una norma, esto es, de un concreto sentido de un precepto, y se responde sobre la sí constitucionalidad de otro 
sentido o interpretación de dicho precepto) no supone sustituir el dubio planteado por el juez a quo por otro diferente para de este modo, en este juego malabar, sustraerse a la necesidad de pronunciar la inconstitucionalidad que de. la adecuación a tal petitum inevitablemente se deduciría? Probablemente sí, lo que tanto vale como decir que con tal tipo de sentencias se está institucionalizando en el campo de la justicia constitucional un cierto grado de «incongruencia», esto es, de divorcio entre la demanda y el subsiguiente pronunciamiento.

Explicar, visto lo anterior, ese tendencial desfase que se aprecia entre teoría y praxis (y con ello determinar el exacto «modo de ser» del principio de congruencia en el ámbito del proceso constitucional) exige, pues, plantear el problema en términos de mayor realismo. Ocurre inevitablemente que el juez constitucional está vinculado, sin que deban caber dudas sobre ello, al principio de congruencia. Pero no lo está, en cambio - lo cual no puede dejar de modificar su cualidad o entidad más íntima-, a la condición que hace eficaz a dicho principio, esto es, a la amenaza de revisión de sus fallos incongruentes por una instancia superior y en razón precisamente de dicho vicio de incongruencia.

El juez Jackson decía en el marco de la justicia constitucional americana: «Los jueces del Tribunal Supremo no somos el final porque seamos infalibles... sino porque somos el final.» $\mathrm{Y}$ esa es aquí la realidad última del problema: no se trata de que la mencionada vinculación no exista, sino de que su eficacia queda inevitablemente a merced del propio Tribunal, esto es, de la interpretación que el mismo - actuando ya una voluntad que es política - haga en cada caso y en cada sistema de su propia posición dentro del esquema institucional.

Congruencia, pues, pero congruencia con fisuras por donde el juez constitucional canaliza en ocasiones sus tentaciones como poder.

\section{PRINCIPIO DE MOTIVACION}

El segundo de los principios enunciados, el principio de «motivación», es consustancial a la «teoría de la sentencia» desde que su necesidad apareciera prevista por la Ley francesa de 16-24 de agosto de 1790. Advirtamos además que, para nosotros, tal principio tiene el interés de colocarnos ante un tema a la vez crucial e insuficientemente construido, como corresponde a la juventud de la jurisprudencia en que se apoya: el tema de los vicios de inconstitucionalidad. Porque, a fin de cuentas, la pregunta que efectivamente toca fondo en el problema de la motivación de las sentencias constitucionales (aparte obviedades en torno a su disposición en consideraciones «de hecho» y «de derecho» que aquí quedan excusadas) se orienta a saber qué causas, qué «vicios» permiten motivar o fundamentar la decisión de que una ley o un acto cualesquiera son inconstitucionales.

1. No hay problemas por lo que respecta al reconocimiento frontal de los dos más visibles y frecuentes motivos de inconstitucionalidad; de ahí que, 
aunque ellos cubran con mucho el más elevado porcentaje de decisiones en toda jurisdicción constitucional, su recuerdo pueda quedar aquí reducido -siempre que ello no distorsione nuestra apreciación de su exacta importancia- al escueto enunciado de tales categorías.

Me refiero, claro está, al vicio de inconstitucionalidad material o sustantiva consistente en la inadecuación entre el acto sometido a control y el contenido sustantivo - las disposiciones inmediatas para la vida - previsto en un concreto mandato constitucional; valga como ejemplo, donde tantas y tantas decisiones jurisprudenciales serían alegables, la sentencia dictada por el Tribunal Constitucional yugoslavo el 22 de noviembre de 1973, en la cual se declara la inconciliabilidad del contenido de determinados preceptos del Reglamento de relaciones laborales de la empresa «Ostrelj» de Bosanski Petrovac, los cuales encomiendan ciertas decisiones relativas a los trabajadores al Comité Ejecutivo de la empresa, con la enmienda constitucional número XXI, la cual, como aplicación del principio de autogestión, considera que tal tipo de acuerdos debe ser adoptado directamente por los obreros.

Y me refiero también, por supuesto, al vicio de inconstitucionalidad por defecto de competencia, producido cada vez que un órgano actúa ultra vires de sus atribuciones constitucionales e invadiendo, por tanto, las ajenas; tal es el caso contemplado en la sentencia constitucional alemana de 6 de febrero de 1978, que anula la Ley sobre Objetores de Conciencia de julio de 1977, entre otras razones, por haber desconocido - punto en el cual disentía el juez Hirsch- la competencia que al Bundesrat reconoce el artículo 87.b de la Grundgesetz.

2. El planteamiento pasa, en cambio, a ser mucho menos pacífico cuando se refiere a la posibilidad de apreciar la inconstitucionalidad de la ley por vicios de forma o in procedendo, esto es, por defectos producidos a lo largo de su procedimiento de elaboración parlamentaria.

La razón fundamental, claro está, es que con ello se pone sobre el tapete el delicadísimo problema -iproblema que empieza a ser ya de «frontera entre poderes»!- - de la admisibilidad o no del control sobre los interna corporis, es decir, sobre los actos internos de las Cámaras que integran el poder legislativo; posibilidad esta que la doctrina tradicional (Hatschek, Craushaar...) siempre había rechazado y a la que lógicamente los Parlamentos se han opuesto también con explicable y no disimulada beligerancia.

El tema se planteó con abierta crudeza en 1959 en Italia, donde el presidetıte de la Cámara de Diputados, requerido por el juez ponente de la Corte Costituzionale, Tomaso Perassi, se negó a remitir al Tribunal copia del texto taquigráfico de las sesiones de determinada Comisión alegando que tales trabajos constituían interna corporis acta, de los que el Tribunal no estaba legitimado para conocer. Sin embargo, ya en esta oportunidad primera, la sentencia entonces recaída, la número 9, de 9 de marzo de 1959, logró imponer frente a la Cámara de Diputados - que ya antes del fallo había flexibilizado su postura- la tesis de la «controlabilidad de los interna corporis», es decir, de la admisibilidad de «il controlo di un antico feticio: gl'interna corporis...», conforme expresaba el título de un famoso artículo de Barile aparecido ese mismo 
año en la revista Giurisprudenza Costituzionale. Y aunque no los compartamos, hay que admitir que aquella decisión histórica vino a sentar.la posibilidad de tal control en unos términos (después reafirmados por la sentencia número 119 , de 1969) que aún hoy constituyen la opinión más generalizada, por mucho que, a nuestro entender, disten todavía de ser satisfactorios: en la competencia del Tribunal - tal es la tesis acogida por dicha sentencia- entra, senza dubbio, el control de los interna corporis materialmente previstos en el texto constitucional, pero no, en cambio, el de aquéllos exclusivamente regulados por los Reglamentos de las Cámaras.

Evidentemente, suscribir dicha doctrina equivale a tanto como a olvidar - expresemos por fin la causa de nuestro desacuerdo- que la subordinación del iter legis al Reglamento parlamentario es también una exigencia constitucionalmente impuesta en la medida en que es inseparable de la previsión constitucional del Reglamento mismo, que es previsión de la sumisión de tales actos al Reglamento, o no es nada. Y ello aun por encima de la evidencia de que aquélla es la solución en que se encuentran también ancladas la más antigua jurisprudencia constitucional del mundo, la de los Estados Unidos (sentencia United States $v$. Ballin, por lo que respecta al Tribunal Supremo de la Federación; sentencia State v. Brown, del Tribunal Supremo de Carolina del Sur, o sentencia Miller $v$. Oelwein, en Iowa, entre otras), e igualmente la jurisprudencia constitucional alemana (según sentencias de 14 de octubre de 1970 y de 5 de marzo de 1974, del Tribunal Constitucional Federal, conforme a una orientación que ya habían preludiado incluso muy tempranamente las de los Tribunales Constitucionales de ciertos Länder, entre ellas la sentencia de 5 de noviembre de 1948, en Renania-Palatinado, o las sentencias 1, 2 y 3 de 1962, del Staatsgerischtshof de Baja Sajonia).

La lógica interna de tan discutible como compartida tesis apunta a una razón sólo aparentemente convincente: es éste - se mantiene- un modo «práctico» (convencional y salomónico, pero útil) de distinguir entre vicios de forma que son esenciales, esto es, que afectan a la esencia del acto y deben causar la nulidad del mismo (= identificados sin más con los referidos a actos internos constitucionalmente previstos), y vicios de forma que no son esenciales y que, por tanto, no deberían provocar tal nulidad (= identificados con aquellos que afectan a interna corporis acta sólo reglamentariamente previstos), evitando así que el más insignificante defecto en el iter legis - mirada con lupa, ¿qué ley no lo tiene?- desemboque en una sanción tan desmedida y fuera de lugar como la anulación de la norma correspondiente.

¿Qué decir al respecto? Pues que entiendo que alguien crea que ahí hay un valor argumental atendible. Pero que, sin embargo, cualquiera que sea su innegable comodidad, me parece que ésta es una solución lógicamente gratuita y técnicamente incorrecta: porque, si medimos su lógica, está claro que la justicia de semejante tesis oscila arbitrariamente en razón de la mayor o menor minuciosidad del texto constitucional de que se trate, $y$, aun entre Constituciones igualmente detalladas, nada asegura que los trámites verdaderamente afectantes a la esencia del acto legislativo vayan a estar previstos, todos y sólo ellos, en la Constitución y nunca en los Reglamentos de las Cámaras. Pero es que además, si encaramos el problema desde un punto de vista rigurosamente 
técnico, lo único correcto sin duda (aunque ello exija, claro está, un esfuerzo jurisprudencial mucho más intenso) es sentar como presupuesto la controlabilidad de todos los interna corporis y a partir de aquí iniciar una ponderada y prudente construcción jurisprudencial que depure progresiva y casuísticamente - con la riqueza de lo que está vivo y no con la comodidad de las presunciones globales- qué vicios de forma deben ser, son efectivamente esenciales, invalidantes..., y cuáles no.

3. En cualquier caso; admitidos todos los desacuerdos imaginables respecto del alcance con que hayan de ser apreciados los vicios de forma, más conflictiva aún es la cuestión en torno a si cabe o no incluir entre los vicios de inconstitucionalidad fórmulas que permitan hacer avanzar el control hasta esa delicadísima zona que es la detectación de vicios producidos en el ámbito de la actividad discrecional del poder legislativo; cuestión esta en la cual lo que comienza a estar en juego es el admitir o no que el Tribunal Constitucional pueda llegar a convertirse en algo muy semejante a una pura jurisdicción de mérito o de oportunidad, esto es, que pueda entrar a conocer - $-\mathrm{y}$ pienso que los enunciados hablan aquí por sí solos-, de los fines que han determinado la actuación del legislador, del correcto o incorrecto uso que el mismo haya hecho de su potestad legislativa e incluso de la solidez o insolidez del razonamiento que está en la base de la ley misma.

Si dejamos aparte sentencias constitucionales de signo contrario al reconocimiento de esa posibilidad, como la japonesa de 6 de diciembre de 1959, en la que el Tribunal llega a tanto como a asumir la doctrina del «acto político» (explícito reconocimiento de espacios discrecionales reconocidos al Parlamento y sustraídos a su control) para eximirse así de declarar la inconstitucionalidad del Tratado de Seguridad yanky-nipón, cuya oposición al artículo 9 de la Constitución japonesa es evidente, la primera respuesta de la jurisdicción constitucional al problema enunciado ha consistido, pura y simplemente, en importar al terreno de la sentencia constitucional determinadas categorías acuñadas por el Derecho administrativo:

a) Clara es la recepción por el Tribunal Constitucional Federal Alemán del principio de proporcionalidad de medios a fines, presente en infinidad de sentencias como la de 11 de junio de 1958, sobre la ley bávara de farmacias, sentencia de avanzadilla (aunque fuertemente criticada por Ernst Forsthoff; véase el penúltimo capítulo de -su Der Staat der Industriegesellschaft, 1971), en la que el Tribunal llega a tanto como a decidir, argumentando precisamente desde la adecuación o inadecuación entre el sistema optado por la ley (el sistema de concesión) y el fin (satisfacer las exigencias de un suficiente abastecimiento farmacéutico), en base al cual el legislador justificó dicha opción; cabría añadir que los márgenes de aceptación de esta técnica de control en la mencionada jurisprudencia constitucional alemana han sufrido y siguen sufriendo, eso sí, oscilaciones, desde la generosa y arriesgada posición adoptada por la sentencia de 22 de mayo de 1963, sobre la ley de Impuestos al Transporte, que parece admitir nada menos que la posibilidad de que el juez constitucional se reserve el derecho de juzgar sobre la «proporcionalidad» de determinada medida normativa, no en el momento, y atendida su presumible ade- 
cuación al fin, sino transcurrido el tiempo, y a la vista de los resultados reales y efectivos..., hasta la posición infinitamente más prudente en que se ha situado la sentencia de 9 de marzo de 1971, en la cual se afirma que la determinación de fines y medios constituye una decisión política, y que una medida legislativa no es inconstitucional por el sólo hecho de estar fundada en un pronóstico inexacto, lo que no significa que el Tribunal no pueda examinar la proporcionalidad medios-fines, pero sí que sólo debe poder hacerlo de forma y con criterio restrictivos; de todos modos, no es preciso aclarar que tales oscilaciones afectan a la intensidad con que se reconoce, nunca al reconocimiento mișmo, por la citada jurisdicción alemana, de dicho mécanismo de control.

b). Igualmente visible es la utilización por los Tribunales Constitucionales del criterio de interdicción de la arbitrariedad; valga como ejemplo la sentencia del Tribunal Constitucional de Hesse, de 28 de noviembre de 1973, producida en una zona tan constitutivamente discrecional como es el «derecho de. gracia», y en la cual - aunque no es el pronunciamiento que correspode al caso debatido- se sienta la doctrina de que el ejercicio del derecho de gracia no es una facultad enteramente discrecional para el ministro-presidente de Hesse; antes bien, una sentencia constitucional puede llegar a juzgar que tal decisión está constitucionalmente viciada si no ha estado precedida de una información adecuada sobre las circunstancias del caso (esto es, si se constata que no se solicitaron determinados informes de los centros penitenciarios o ciertos dictámenes periciales, médicos, policiales, etc.), porque, en un Estado de Derecho, toda autoridad está impedida de actuar de forma arbitraria.

c) $\mathrm{Y}$ no menos explícita es la incorporación a la jurisprudencia constitucional del vicio de inçonstitucionalidad por exceso de poder, reivindicado ya por Mortati en un premonitorio trabajo, Sull'eccesso di potere legislativo; aparecido en 1949. A la idea de exceso de poder se ciñe, por ejemplo, el esquema.argumental de la sentencia alemana de 7 de julio de 1971, por la que el Tribunal admite la constitucionalidad de la ley sobre propiedad artística en el precepto que obliga a los autores a no oponerse a la reproducción de su obra en libros de texto (pues su derecho de propiedad cede ante el fin social de la formación de la juventud), pero no así en aquella otra norma que además les impide ser retribuidos por ello, pues ese nuevo recorte a su derecho excede del fin citado. E igualmente oportuno es recordar aquí la comentadísima sentencia italiana de 7 de marzo de 1964, sobre nacionalización de empresas eléctricas, que lleva su celo a enumerar - con rigor de Manual- las cinco causas que permitirían apreciar tal exceso de poder legislativo: ausencia de apreciación de fines y de medios por el órgano legislativo; intervención en eșa apreciación de criterios ilógicos, arbitrarios o contradictorios; evidente contradicción entre dicha apreciación y los datos de hecho; absoluta inadecuación o falta de idoneidad de los medios respecto de los fines pretendidos, $o$, en fin, desviación respecto del fin de utilidad general señalado por-la norma constitucional. Incluso la jurisprudencia constitucional japonesa ha torcido su curso en la sentencia de 4 de abril de 1973. (que además reviste la singularidad de ser una de las tres únicas sentencias japonesas con apreciación positiva de inconstitucionalidad, según datos del profesor Yoichi Higuchi, de la Uni- 
versidad de Tohoku) para anular por exceso de poder legislativo el artículo del Código Penal japonés, que agravaba desmesuradamente la pena del parricida frente a la del asesino no cualificado; el Tribunal reconoce al legislador la capacidad de apreciar discrecionalmente la diferencia gradual que separa. a unos de otros comportamientos, pero considera que esa discrecionalidad tiene unos límites razonables; en el caso presente, el precepto de referencia es anulado porque, incidiendo en un claro «exceso de poder legislativo», el legislador ha agravado la pena en términos que van más allá de lo que sería una apreciación prudencial de la cualidad singular de la conducta del parricida.

Sin embargo, más allá de este desembozado trasvase de técnicas propias del Derecho administrativo al campo que nos ocupa, el verdadero reto de la jurisprudencia constitucional se encuentra, lógicamente, en decantar unas formas propias de control de discrecionalidad, esto es, en explicitar unas técnicas adecuadas al específico tipo de relaciones que se establecen entre el legislador y el texto constitucional. $Y$, aunque esa elaboración está aún absolutamente in fieri, dos líneas de avance parecen - con todo- detectarse.

Una de ellas se orienta en el sentido de la perfección de las técnicas de interpretación constitucional. Lo cual no carece de justificación, pues si la causa fundamental de la discrecionalidad de que acaba disponiendo el legislador se apoya precisamente sobre la constitutiva extensión semántica de la norma constitucional (tejida inevitablemente en base a «decisiones fundamentales» o «cláusulas de valor general», a las que se unen un buen número de «conceptos válvula», para usar el expresivo término acuñado en 1904 por Wurzel o de típicos «conceptos jurídicos indeterminados»...) es lógico que la actual tendencia - tan visible en Alemania- a replantear la teoría de la interpretación en términos de «teoría de la concreción» (Konkretisierung), al dotar al juez de un instrumental adecuado para operar sobre aquella indeterminación, redunde necesariamente en una simétrica reducción de la discrecionalidad del legislador.

A su vez, la segunda de esas líneas habría que buscarla en la progresiva decantación por el Tribunal Constitucional italiano (aparte ahora referencias al caso alemán, que también podrían hacerse) del criterio de irragionevolezza o irracionalidad como un nuevo vicio que, con apoyo decidido en el principio de igualdad del artículo $3.1 .^{\circ}$ de la Constitución, sustituiría con ventaja al «exceso de poder» - del que, de todos modos, resta fronterizo - a la hora de revisar la discrecionalidad del legislador. Para llegar hasta ahí ha sido preciso, claro está, hacer que el citado principio de igualdad trascienda su estricto significado como valor de naturaleza sustantiva -cual es apreciado, por ejemplo, en la jurisprudencia americana - hasta quedar convertido en un parámetro de proyección o alcance general que, en la medida en que impide al legislador obrar arbitrariamente, «irrazonablemente», permite al juez constitucional entrar a revisar, con toda la profundidad que se quiera, la coherencia (= la lógica y las razones) de la ley misma. Ello, en consecuencia, supone extender el control de constitucionalidad de las leyes hasta la apreciación de sus «motivos» o «criterios racionales», según la sentencia de 11 de julio de 1961, o hasta el replanteamiento de sus «cánones de racionalidad», conforme afirma la sentencia de 12 de diciembre de 1972; y supone hacerlo 
en términos tales que han inclinado a Giuseppe Volpe a hablar de un auténtico juicio sobre -es el título de un discutido y discutible reciente libro suyo- «la injusticia de las leyes». Añadamos, además, que se trata de una técnica in crescendo: en 1975-1976, por citar una etapa con cifras llamativas, 32 de las 44 sentencias italianas que apreciaron positivamente la existencia de inconstitucionalidad ( $=$ un 75 por 100 ) se apoyaron en el artículo 3 y en el parámetro de la irragionevolezza.

En fin, la sola exposición de los términos en que está planteado el problema nos da idea del tipo de frontera, última, apasionantemente sugerente... $\mathrm{y}$, sin embargo, extremadamente lábil, en que nos encontramos. Es el momento de recordar que, mientras tales apreciaciones orientadas a poner cerco a la discrecionalidad del legislador se funden - como deben- en la infracción de ciertos límites más o menos reconductiblemente normados desde la Constitución, este control será todavía «control de ilegitimidad constitucional» y no - lo que nunca debe ser- «control de mera oportunidad», en el que los criterios del legislador acabarían siendo peligrosamente sustituidos por las propias opciones del Tribunal.

Sin embargo, el problema está en saber si esa línea divisoria entre «legitimidad» y «oportunidad» es siempre fácilmente definible: Calamandrei calificaba de «bien intencionada ingenuidad» el artículo 28 de la Ley italiana de 11 de marzo de 1953, que excluye del control de constitucionalidad «ogni valutazione di natura politica e ogni sindacato sull'uso del potere discrezionale del Parlamento»; y Giuseppe Branca, activísimo presidente del Tribunal Constitucional italiano entre 1969 y 1971, ha colocado la cuestión en sus exactos términos, al recordar que «algunas sentencias no pueden dejar de ser fruto de opciones políticas... porque son definición de principios que, estando en el vértice del ordenamiento, son principios políticos».

4. Tal vez éste sería el momento oportuno para añadir, a tal catálogo de vicios o defectos que permiten fundamentar una sentencia constitucional, cuando menos la sugerencia en torno a si es posible o no apreciar inconstitucionalidad por vicio de omisión, esto es, por apoyo en lo que la doctrina alemana (Schneider, Wessel, Lechnes...) llama «Unterlassungen des Gesetzgebers» y la doctrina italiana (Mortati, en un célebre trabajo aparecido en Il Foro Italiano, en 1970; Nicola Picardi, en sendas aportaciones de 1977 y 1979 sobre «sentenze integrative»...) denomina «comportamenti omissivi del legislatore».

La extremada delicadeza política de tal supuesto no necesita ser destacada: implica nada menos que el eventual paso del «control negativo» al «control positivo» de constitucionalidad; en otras palabras, viene a suponer no tanto la negación o anulación de lo que, siendo inconstitucional, fue puesto por el legislador, cuanto la adición (en una arriesgada, sorprendente y discutiblemente subrogatoria intervención normativo-positiva) de aquello que, siendo constitucionalmente debido, el legislador dejó de poner.

Pero, puesto que después hemos de volver sobre el tema - y en aras de una economía de tiempo que se nos impone inevitablemente-, digamos sólo aquí que la jurisprudencia italiana está intentando abrir brecha en ese camino 
a través de sentencias constitucionales como las números 156 y 167 de 1976 y las números 105 y 153 de 1977, entre muchas, las cuales declaran la inconstitucionalidad de una ley «nella parte in cui non prevede» o «nella parte in cui non dispone» algo que constitucionalmente no debía haber sido omitido.

5. Y terminemos, en fin, este repaso a las posibles motivaciones sobre las que puede apoyarse una sentencia constitucional, recordando que la doctrina rechaza únicamente - en razón de la condición institucional y colegiada del sujeto- la posibilidad de que los Tribunales constitucionales puedan apreciar la existencia de vicios afectantes a la voluntad del legislador, como lo serían el error, el dolo o la violencia.

Sin embargo, tan categórica y desautorizante respuesta podría ser un tanto apresurada. La Corte constitucional italiana (aunque la desestimara, poniendo en juego una espléndida doctrina) ya hubo de hacerse cargo de una demanda -véase sentencia de 7 de marzo de 1964- que pedía la anulación de una ley por «violencia», dado que, tras la votación de la misma, un número de diputados suficiente a privar a dicha ley de la recién alcanzada mayoría declaró haberla votado contra su propio criterio y tuertemente constreñido por la disciplina de partido. Y, por lo que respecta a la posibilidad de «dolo», casos como el de la Ley siciliana de 29 de junio de 1950 -recordado por Virga-, en el que la mayor parte de las firmas populares que sirvieron para iniciar el procedimiento legislativo resultaron ser después falsas, ayudan a pensar que en esta zona es preciso proceder con mucha mayor ponderación y prudencia.

\section{PRINCIPIO DE COLEGIALIDAD}

En un terreno absolutamente diferente, en el terreno de la condición orgánica o colegial de la voluntad que respalda a la sentencia, se sitúa el tercero de los principios enunciados: el principio de colegialidad.

Si dejamos aparte la cuestión del eventual empate a votos, oportunamente resulta por el artículo 15 de la Bundesverfassungsgerichtgesetz a favor de la imposibilidad de pronunciar la inconstitucionalidad en tan indecisas condiciones y no tan oportunamente decidida en Italia, o entre nosotros, con la apelación al voto de calidad del presidente..., la cuestión realmente compleja, interminablemente debatida, que aquí se plantea es la postura a adoptar ante las dissenting opinions u opiniones disidentes de aquellos jueces que se encuentran en abierta contradicción con el pronunciamiento que deben respaldar como colegio.

La alternativa, desde luego, está francamente resuelta a favor del dissent en la jurisprudencia constitucional americana, dado que tal posibilidad es uno de los datos más definitorios, más genuinamente constitutivos, de la tradición jurídica anglosajona. Ese disentimiento puede ser expresado en forma profusamente doctrinal o puede reducirse, como en el caso Burck v. Bell (1927), a un escueto Mr. Justice Butler dissents, pero habitualmente acompaña a las sentencias constitucionales del Tribunal Supremo de los Estados Unidos, donde son normales las decisiones four to five y donde, en cambio, 
son relativamente extrañas las sentencias unánimes, ayunas de disidencias expresas. Hace falta, a veces, que el Tribunal entienda la necesidad de presentar una postura muy sólida ante un problema muy delicado (como en el caso Brown v. Board of Education, 1954, que puso fin a la segregación racial en las escuelas) para que esa unanimidad prime. En cualquier caso, para el jurista americano, la utilidad de este instituto está fuera de todo debate, porque, como recuerda el profesor Aikin, de la Universidad de California, en The role of Dissenting Opinions in American Courts (1968), ese jurista sabe muy bien que el dissent de hoy es, con atendible frecuencia, la opinión dominante de mañana.

El problema es mucho más complicado, en cambio, en los países de tradición continental, donde se ha defendido siempre la más anónima colegialidad como garantía de respaldo compacto y firme para las sentencias.

Los temores aquí han apuntado tradicionalmente a la pérdida de prestigio de una justicia que se exterioriza dividida y a la creciente politización de los juicios que el dissent pudiera comportar. A ello habría que añadir, asimismo, lo nada estimulante de ciertas experiencias habidas en el constitucionalismo de entreguerras: recuérdese aquí, sin más (sentencia de 5 de noviembre de 1934, sentencia de 14 de diciembre de 1935 y sentencia de 5 de marzo de 1936), lo que fue la práctica de tales «votos particulares» durante nuestra Segunda República, al amparo del artículo 41 de la ley Reguladora del Tribunal de Garantías Constitucionales. En consecuencia, tras la Segunda Guerra Mundial, ni el artículo 30 de la Bundesverfassungsgevicbtgesetz ni el artículo 18 de la norrna integradora italiana de 1956, al regular el sistema de adopción y exteriorización de las sentencias constitucionales, reconocieron el dissent.

Sólo el tiempo, erosionando mentalidades y desgastando viejos prejuịcios, ha permitido que finalmente acabe abriéndose también. en este área de la cultura jurídica continental -y con referencia casi exclusiva al ámbito de la justicia constitucional - una corriente favorable a dicha práctica.

El tema quedó replanteado en Alemania hacia mitad de la década de los sesenta con contribuciones como las de Zweigert, Heyde o Nadelmann, o como la de Rupp en el Festscbrift für Leibbolz, a las que bien podría unirse la ponencia presentada por el profesor Freisenhahn al Juristentag de 1968, decididamente volcada en la defensa del Sondervotum u «opinión disidente» con apasionamiento que quedó reflejado en las conclusiones de dicho Congreso. En el terreno de la práctica, por su parte, el dissent había sido introducido previamente en las jurisdicciones constitucionales de Bremen y de Baviera; y, a nivel federal, había hecho alguna aparición en aquellas sentencias - como la del «caso Spiegel», de 5 de agosto de 1966_, en las que el empate a votos, precisamente porque bloqueaba la decisión, obligaba a explicar las opiniones en contraste; la Sala Segunda del Tribunal. Constitucional había realizado, en fin, una tímida avanzadilla y, desde el 2 de mayo de 1967, estaba incluyendo al menos en todas las sentencias una referencia numérica al reparto de votos. De este modo, en la desembocadura de todo este proceso, y como consecuencia de tan insistente preparación, la Ley alemana de 21 de diciembre de 1970 modificó el artículo 30 de la Bundesverfassungsgericbtgesetz, admitiendo, en su párrafo segundo, la posibilidad de las dissenting opinions; 
y aún se diría que la nueva norma se aplicó impacientemente, porque su primera utilización se produjo en la famosa sentencia de 15 de diciembre de 1970, sobre escuchas telefónicas, emitida seis días antes de la promulgación de aquella reforma.

Por el dissent, asimismo, ha acabado inclinándose la única experiencia de justicia constitucional habida en ese contexto singular que son los países socialistas: me refiero, claro está (pues la aplicación del cap. VI de la Constitución checa de 1968, tras los sucesos de la primavera de Praga, ha quedado congelada en términos de no llegar a designarse nunca los jueces del Tribunal Constitucional que aquí se prevé), al caso yugoslavo; el artículo 391, de cuya Constitución de 1974 llega incluso más lejos que la citada regulación alemana, al convertir a dichas «opiniones disidentes» en un auténtico «deber constitucional», ya que, conforme a dicho precepto, el juez discrepante tiene no la posibilidad, sino la obligación de formular tal voto, haciéndolo además de modo razonado. «El miembro del Tribunal Constitucional - se lee en aquella norma- que se oponga a la decisión tomada por el Tribunal tiene el derecho y el deber de formular su opinión y de desarrollarla por escrito.»

Inverso ha sido, en cambio, el proceso en la experiencia italiana. Al dissent no le han faltado allí defensores de la talla de Lombardi, Lavagna e, incansablemente, Mortati antes incluso de su vigorosísima intervención en la Mesa Redonda sobre Justicia Constitucional, celebrada en Florencia en 1965, ocasión en la cual, por cierto, concordaron con él los también jueces Sandulli, Branca y Crisafulli; sin embargo, las resistencias de determinados medios italianos han sido tan fuertes - tal vez juegue allí el temor a la división del colegio de jueces en una sociedad ya de por sí dividida-, que el Proyecto de de Ley Constitucional, depositado el 9 de julio de 1973, en el que se preveía la admisión de tales «opiniones disidentes», apenas ha pasado de dicho trámite de depósito. De todos modos (como recuerda Massera en su espléndido análisis dedicado a esclarecer determinados aspectos del funcionamiento efectivo de la Corte Costituzionale), los jueces del Palacio de la Consulta suplen muy «a la italiana» la ausencia del dissent, compensándolo con una nada comedida «fuga de noticias»: en la experiencia italiana no son nada infrecuentes sucesos como la aparición del juez Mortati, el 14 de noviembre de 1969, en un debate televisado, avanzando cuál sería su postura en un caso aún sub julice, lo que provocó una airada protesta en la sesión del 27 siguiente en la Cámara de Diputados, o - aunque el dato no esté en Massera- como la carta de Crisafulli, juez, a Barile, publicada en el Corriere della Sera de 18 de enero de 1973, para aclarar el significado de la famosa sentencia recaída en el caso «Cordero».

En fin, si terminamos pasando del contexto a la valoración, podríamos concluir que: 1) El dissent es cierto que «contribuye a la mejor comprensión de las decisiones... y a la renovación del Derecho constitucional», como expresamente hiciera constar la Comisión del Bundestag que elaboró la reforma de 1970. 2) Es también inevitablemente evidente que politiza algo las actitudes de los jueces, lo cual - por lo demás- sólo es grave si éstos no aciertan a ejercer un cierto self-restraint sobre la tentadora espectacularidad que puedan comportar las connotaciones políticas de su disentimiento. 3) Y es, finalmente, 
notorio que sólo afecta a la independencia de los miembros del Tribunal en el caso en que éstos sean reelegibles (por cierto, dissenting y reelegibilidad coinciden, aunque con un interregno de tres años, en la regulación española), en cuyo supuesto, claro está, la posibilidad de expresar el dissent fácilmente se convierte en un instrumento de disciplina de partido sobre el juez que desee ser propuesto en una nueva oportunidad.

\section{PRINCIPIO DE EFICACIA}

Tras el recorrido anterior, la sentencia no alcanza todavía el punto de arribo que institucionalmente la justifica: la reintegración del ordenamiento constitucional al que la ley o el acto inconstitucionales han lesionado. Esa es la frontera del último de los principios que originariamente enunciamos: el principio de eficacia, el cual nos sitúa ante dos cuestiones - «efectos», «efectividad»- complementarias $y$, sin embargo, de muy diverso tenor.

1. La primera de ellas es de orden prioritariamente técnico, y tiende a determinar los efectos de tal declaración de inconstitucionalidad. Como es bien sabido, tres son los sistemas que constituyen aquí las respuestas al uso: 1) El sistema americano, en el que esa eficacia sólo se produce inter partes, confiándose su extensión a la técnica del stare decisis. 2) El sistema austríaco, puro o kelseniano, donde la sentencia, ya con una pretensión de eficacia erga omes, tiene una entidad «constitutiva» (es ella misma, en virtud y a partir de su pronunciamiento, quien «pone» la inconstitucionalidad en el mundo de lo existente jurídico) y donde, en consecuencia, los efectos sólo se producen ex nunc, es decir, desde ahora y hacia el futuro; sistema en el que, tal vez por ello, las únicas y excepcionales quiebras que en esta determinación del momento inicial de la eficacia se admiten no operan hacia atrás, sino hacia adelante, en forma de reconocimiento (art. 140.5 de la Constitución austríaca) de la posibilidad de que el Tribunal Constitucional pronuncie (valga por todas la sentencia austríaca de 19 de diciembre de 1972) las llamadas «sentencias de eficacia aplazada» o «de eficacia retardada», en las que el Tribunal determina, por graves razones de interés público implicadas en la eventual ejecución inmediata, que la declaración de inconstitucionalidad que se adopta no debe comenzar a ser efectiva hasta pasado un cierto plazo que en tal pronunciamiento se concreta y que, conforme a la normativa austríaca, nunca debe ser superior a un año. 3) $\mathrm{Y}$, en fin, el sistema reformado, variante avanzada del anterior, adoptado en parte en Alemania e Italia, pese al aparente tenor de ciertos preceptos, en el que la sentencia se entiende no como "constitutiva» ella misma, sino como meramente «declarativa» de una nulidad que, porque existe ex Constitutione, preexiste a la sentencia y debe, por tanto, causar efectos ex tunc o hacia atrás, planteando así el problema de qué relaciones sociales (las ya agotadas y difícilmente reversibles; aquellas cuya corrección implicaría una cierta superior onerosidad sancionadora...) deben quedar excluidas de dicha eficacia retroactiva. 4) Fuera casi de esquema - primado sólo por su originalidad y por sus potencialidades inéditas, nunca porque pue- 
da parangonarse en importancia con los anteriores- podría añadirse a los citados un cuarto e imaginativo sistema: el que fuera cuanto menos sugerido y discutido en la Asamblea constituyente italiana, conforme al cual la declaración de inconstitucionalidad correspondería al Tribunal, pasando a ser competencia posterior del Parlamento el poder-deber de concretar las consecuencias de esa declaración y de determinar sus efectos.

2. Por supuesto que el conglomerado de problemas que la cuestión relativa a los «efectos» de la sentencia constitucional viene a plantear (efectos sobre procesos en marcha, efectos sobre el proceso a quo, efectos sobre relaciones agotadas, conciliación con «cosa juzgada», especificidades de esa eficacia en el caso de leyes penales, o de leyes procesales, o de leyes tributarias, etc.) excede con mucho del apretado esquema en que acabamos de comprimirlo. Soy el primero en ser consciente de ello. Pero permítaseme dejar ahí su consideración, en parte porque es ésta la zona más tratada del tema que nos ocupa, la que puede resolverse en cualquier manual, y en parte porque -a la hora de ponderar mi reparto del tiempo y del esfuerzo en esta exposiciónpienso que la verdadera «eficacia» de la sentencia constitucional no se acaba jugando en el plano escuetamente jurídico de la determinación de sus «efectos», sino en el mucho más político de su «efectividad» frente a los demás poderes, esto es —una vez más, pero ahora explícitamente- en el plano de su entidad como acto de poder.

Sea la mejor prueba de cuanto decimos la consideración de los tres frentes en los cuales esa efectividad se decide:

A) El primero de tales «frentes» afecta a la ejecución material de la sentencia. Esa ejecución debe canalizarse (art. 35, in fine, de la Ley alemana, o art. 92 de la nuestra) utilizando la estructura orgánica de los demás poderes. Pero, precisamente por ello, puede tropezar con la resistencia u obstrucción de cualquier otro poder $\mathrm{y}$, muy particularmente, de ese concreto poder al que tal encargo se haga. En la historia constitucional americana quedan todavía las huellas de la intemperancia del presidente Jackson tras la sentencia Cherokee Nation v. Georgia: «El Juez Marshall ha dictado sentencia..., ahora tendrá también que ejecutarla.»

Pero el problema no es sólo de ayer. A su lado se podrían recordar casos de resistencia tan espectaculares - iy tan de hoy! - como la circular del Ministerio de Justicia italiano, de 5 de abril de 1970, que hizo imposible el cumplimiento de la sentencia núm. 133 del mismo año; o como esa especie de «frente común» que el Consejo de Estado, con sus dictámenes, el Ministerio de Justicia, con sus circulares a las Fiscalías para que no modificaran su práctica anterior, y el Tribunal de Casación, con la reafirmación insistente de su jurisprudencia, organizaron frente a la decisión de 28 de noviembre de 1973 , en la que el Consejo Constitucional francés sentó la inadmisibilidad constitucional de que, a nivel de reglamento, esto es, no mediando ley, pudieran imponerse, por conductas calificadas como faltas, penas que implicaran prisión o privación de libertad.

El artículo 89 de la Verfassungsgerichtshofgesetz austríaca, con apoyo en 
el artículo 146 de la Constitución, ha querido paliar esos riesgos encomendando la tutela de la ejecución de las sentencias constitucionales al Presidente de la República, el cual —se dice expresamente- podrá acudir, a tales efectos, a todos los medios posibles, incluido el recurso al Ejército federal; y en la Constituyente italiana se llegó a proponer que fuese el Tribunal mismo el que, en previsión de resistencias institucionales profundas, tuviese el Ejército «directamente» a su disposición.

Sin embargo, está claro que el nivel del problema es absolutamente otro: no fue el Ejército, sino la tenaz amenaza de dimisión del octogenario primer presidente del Tribunal Constitucional, Enrico de Nicola, lo que forzó al Gobierno italiano a no seguir aplicando - después de anuladas- determinadas leyes de la etapa fascista; y no es el recurso al Presidente de la República, sino la utilización del delito de «desobediencia punible» contra la autoridad que inejecute una sentencia constitucional, lo que, a la postre, puede acabar permitiendo que se hable de verdadera eficacia.

B) No menos fundamental, el segundo de estos «frentes» se produce en el terreno de la reorientación en sentido constitucional del ordenamiento jurídico $\mathrm{y}$, en consecuencia, está abierto a un sin fin de potenciales fricciones con el poder legislativo. A fin de cuentas, la verdadera efectividad de la sentencia que declara inconstitucional un precepto no radica tanto en su anulación (ique, a veces, puede provocar incluso un vacío infinitamente más lesivo...!) cuanto en la reintegración del ordenamiento con una norma ya sí constitucional, llamada a ocupar el lugar de la anulada. Y es evidente que un Parlamento, puesto en actitud elusiva, tiene ante sí infinidad de tácticas: desde el llamado «cumplimiento aparente», esto es, desde la reproducción de la ley en términos prácticamente idénticos (cual pretendiera, por ejemplo, el Proyecto de Ley leído el 12 de junio de 1934 en el Parlamento catalán..., cuatro días después de la sentencia que anulaba la ley de Cultivos) hasta - lo que será más común- la simple pasividad.

Cierto que, en esta pugna, los Tribunales Constitucionales no están inermes:

a) Pueden, en principio, dificultar esa pasividad haciendo explícita en su sentencia la llamada al legislador; tal ocurre con las raccomandazioni incluidas en tantas sentencias italianas, a partir de la de 23 de junio de 1956 (que recomendaba al Parlamento modificar el art. 57 del Código Penal, en el que se establecía la responsabilidad de los directores de periódicos, para adecuarlo al artículo 27 de la Constitución, el cual prevé que la responsabilidad penal sólo es personal; cosa que el legisador hizo por Ley de 4 de marzo de 1958), y tal es, asimismo, el sentido de la institución alemana de la Appellentscheidung, auténtico mandato al legislativo para que sustituya una norma «incompatible con la Constitución» - es la fórmula del art. 31 de la Bundesverfassungsgericbtgesetz- por otra sí conciliable con ella, ateniéndose para ello a los criterios de constitucionalidad e incluso a los plazos que la sentencia le determina; recordemos, entre tantas otras, la sentencia alemana de 31 de mayo de 1978 por la que el Tribunal Constitucional ha reclamado la.intervención del legislador solicitando de éste una ley que restablezca el principio de igualdad en el punto concreto en el que lo vulneraba la Ley de 1 de julio de 1976 al prever que los esposos puedan elegir en el momento de celebrar el ma- 
trimonio, como nombre familiar o común, el del marido o el de la mujer, pero no incluir dicha ley una disposición transitoria que permita hacer lo mismo a los matrimonios celebrados antes de 1 de julio de 1976; lógicamente, ante un caso de inconstitucionalidad en el que la anulación de la norma produce un vacío inevitable o en el que -como en el caso de referencia- ese vacío preexistente por haber nacido precisamente de una omisión del legislador, el restablecimiento de la constitucionalidad (salvo que se prefiera, si ello es posible, el conflictivo recurso a las «sentencias aditivas» o «integradoras») queda a expensas del poder legislativo; pero el Tribunal puede espolearle desde su sentencia, y hay que decir que, generalmente, lo hace con buenos resultados; en el caso citado, el Gobierno federal depositó a fines de 1978 el proyecto de ley que generalizaba aquella posibilidad, y el Parlamento lo convirtió en ley en marzo de 1979.

b) Y pueden también tales Tribunales Constitucionales (la experiencia les avezó a ello desde primera hora) desplegar una estrategia distinta, más agresiva, dirigida no a estimular al legislador, sino, en cierto modo, a sortearlo, a sustituirlo..., recreando jurisprudencialmente el texto afectado de inconstitucionalidad - nunca anulándolo - para que, de este modo, el vacío sobre el que el Parlamento hubiera podido apoyar su pasividad ni siquiera llegue a producirse. Tal es ( $=$ no anular, sino reconstruir en sentido constitucional...) la contundente habilidad y, ¿por qué no decirlo?, la utilidad de las llamadas «sentencias interpretativas». Ello en sus dos versiones: tanto en su disposición como «sentencias interpretativas desestimatorias» o di rigetto, conforme a la nomenclatura italiana, a las cuales se asimilan las sentencias alemanas con «interpretación conforme a la Constitución» (verfassungskonforme Auslegung) cuanto en su conformación como «sentencias interpretativas estimatorias» o «de inconstitucionalidad parcial» (= típicas sentencias de inconstitucionalidad nella parte in cui). En ambas, el texto permanece; pero, eso sí, en unas porque se ha precisado el único sentido que es constitucional y en otras porque se han apeado del precepto ciertos sentidos inconstitucionales, su significado, su campo semántico, ya no coincide de modo pleno con el inicialmente querido por el legislador.

Ahora bien: venir a parar aquí tanto vale como confirmar que este segundo y sustancial «frente» de la efectividad de la sentencia - la reintegración del ordenamiento con normas sí constitucionales- está planteado en términos de inevitable pulso entre poderes.

Eso es lo que explica que las «recomendaciones» tiendan, a veces, a convertirse en lo que no son, en instrucciones detalladísimas que no dejan al Parlamento más tarea que la de dar a aquellas decisiones forma articulada. Tal, en parte, la sentencia alemana de 29 de mayo de 1973 sobre cogestión en las Universidades, en cuanto que vincula al legislador a dictar una norma interfiriéndose incluso, con su detallado criterio, en un tema tan vidrioso y opinable como el de los porcentajes de representación que deben ostentar los diversos estamentos en determinados órganos rectores de la vida universitaria. Y nada sería más expresivo aquí que el recuerdo de las sucesivas sentencias italianas sobre radio-televisión, donde no sólo la sentencia núm. 225, de 9 de julio de 1974 , tras anular ciertos preceptos de la legislación anterior, concretó al legislador siete específicas recomendaciones a las que éste debía atenerse al redactar 
la nueva ley como condición de que el monopolio estatal en dicha materia se considerara constitucional, sino que, dos años después, la sentencia núm. 202, de 28 de julio de 1976, ha anulado a dicha ley nueva como inconstitucional - llegando a eliminar con ello el monopolio del Estado- por no ceñirse estrictamente a los criterios detallados por la sentencia de 1974. Con razón la doctrina ha comenzado a hablar (un tanto enfáticamente, pero no podría decirse que sin justificada alarma) de «sentencias didascálicas», de «sentenciasleyes» o de sentenza delega, como hace Predieri, dado que, por esta vía, el Parlamento viene a quedar en la desairada posición de un mero «legislador delegado».

Y sólo así se entiende, a su vez, por lo que respecta a las sentencias interpretativas, que éstas hayan acabado deslizándose hasta el terreno de las llamadas «sentencias creativas» o «innovadoras», así denominadas precisamente porque no se contentan con determinar cuál, entre los que comporta o contiene, es el sentido constitucional de una ley - frontera que parecería última para este tipo de sentencias-, sino que llegan a manipular de tal modo el texto que introducen en él normas o disposiciones (= sentidos) que antes obviamente no contenía: a) Ese es el caso de las «sentencias sustitutivas», en las que el precepto sigue vigente en cuanto se entienda que no establece «esto», sino «esto otro», cual ocurre en el típico esquema argumental de una de las sentencias constitucionales que más revuelo doctrinal haya causado en Italia: la sentencia de 17 de febrero de 1969, en la que la Corte no sólo declara inconstitucional el precepto que establece la competencia del ministro de Justicia para autorizar a proceder contra ciertos delitos que a ella le afectan, sino que reivindica esa competencia para sí misma, introduciendo de este modo una norma nueva que viene a colocarse en el lugar de aquella creada por el legislador. b) $\mathrm{Y}$ ese es también el supuesto de las «sentencias aditivas» que - recordemos lo dicho sobre inconstitucionalidad por omisión-, apoyadas sobre el argumento de que la ley sería inconstitucional «nella parte in cui non prevede», mantienen su vigencia siempre que se entienda añadido (adicionado, no sustituido por otro) ese contenido que el legislador omitió; tal, la recientísima sentencia italiana, número 56, de 22 de abril de 1980.

Estamos, pues - no hay que explicarlo-, ante una jurisdictio con tentaciones de juris-datio (adviértase que de juris-datio o de «legislador» no precisamente «negativo», como creía Kelsen) y, por tanto, en la más delicada zona de fricción entre justicia constitucional y soberanía parlamentaria.

C) En fin, de la mano de cuanto acabamos de decir se llega al planteamiento del tercero y último de aquellos «frentes» en los cuales hemos convenido que se decide la «efectividad» de la sentencia constitucional: el del valor de dicha sentencia como "doctrina jurisprudencial más fuerte»o, si se quiere, como «interpretación más vinculante» para los demás aplicadores del Derecho.

Visto el problema desde la perspectiva de los Tribunales Constitucionales, reconocer ese valor a sus decisiones es crucial, sobre todo para la eficacia de las cada día más abundantes «sentencias interpretativas», ya que su estrategia (= conservar el precepto adecuando su sentido) se viene abajo si ese sentido, esa interpretación no tiene después capacidad de vincular. 
Sin embargo, no es nada extraño que sea muy otro el planteamiento al cual se siente tendencialmente inclinado el poder judicial, esto es, el conjunto de los Tribunales ordinarios y a su cabeza el Tribunal de Casación del país de que se trate. La doctrina sentada en sus sentencias por el Tribunal Constitucional - sería su tesis- puede teclamar ese valor de «interpretación más fuerte» en cuanto determina el sentido de cualquiera de las normas que integran el texto constitucional, pero nunca (como pretenden sobre todo las sentencias interpretativas) en cuanto afecte al sentido de los términos de la ley ordinaria. Porque, respecto de esta última, si existe algún intérprete constitucionalmente habilitado para fijar su sentido..., ésos son los jueces ordinarios, y si hay alguna que pueda considerarse «interpretación más fuerte»..., ésa es la que realiza el Tribunal de Casación.

En estos términos, pues, queda planteada la que los italianos llaman «la guerra de las dos Cortes».

Cierto que se trata de una «guerra» que parece estar saldada de antemano - hay que decirlo - en perjuicio de los jueces ordinarios: en Alemania a golpe de ley, como prueba la modificación del artículo 31 de la Bundesverfassungsgerichtsgesetz por Ley de 21 de diciembre de 1970, que extiende el valor de «fuerza de ley» (vinculante para todos y, por tanto, para el juez) a ciertas sentencias en las que es más constitutivamente posible que se contengan interpretaciones a las que el juez pudiera querer sustraerse; en Italia, indirecta pero eficazmente, a través de esa especie de técnica overruling que es la doppia pronuncia, esto es, el reforzamiento de una sentencia interpretativa di rigetto (si ello fuera necesario porque el juez ordinario o los demás aplicadores del Derecho no se conformaran a su doctrina) con una posterior sentencia interpretativa de estimación o di accoglimento.

Sin embargo, ello no significa que el problema no reaparezca en forma de recurrentes, casi constantes, escaramuzas. Baste recordar la cerrada argumentación de determinado juez penal (= sólo el fallo vincula..., mientras que la interpretación suele contenerse en los motivos) a la que hubo de hacer frente el Tribunal Constitucional alemán en su sentencia de 10 de junio de 1975, o el abierto enfrentamiento que, en punto a interpretación constitucional, mantiene el Tribunal japonés con los jueces ordinarios encuadrados en la «Asociación de Jóvenes Juristas».

$Y$ aún diría que esas escaramuzas, de las que sobreabundarían los ejemplos italianos, no dejan de tener su efecto: sólo a partir de ellas los Tribunales Constitucionales suelen entrar por la vía de un cierto self restraint capaz de devolver en parte a los jueces comunes su condición de intérpretes de la ley ordinaria.

\section{CONCLUSION}

Creo, en fin, que el tiempo me impone terminar. Lo hago con la esperanza de que este recorrido, cuyo hilo conductor ha querido ser severa y conscientemente jurídico, haya alcanzado también a expresar lo que en la sentencia constitucional hay de intensísima realidad política. Al menos creo haber mos- 
trado cuáles son las brechas por donde se filtran sus tentaciones de poder y cuáles los terrenos en que se sustancian sus colisiones con los demás poderes; en función de lo uno y de lo otro, las decisiones que contienen las sentencias de los Tribunales Constitucionales son —además de resoluciones judicialesactos de neto indirizzo politico.

No hace falta para comprobarlo recordar que la sentencia Dred Scott v. Sandford, de 1857, con sus criterios sobre el problema racial, transformó todo el planteamiento de la campaña electoral de 1860 y precipitó la Guerra de Secesión..., porque es evidente que la sentencia menos espectacular y llamativa acaba trasluciendo igual los criterios ideológicos de sus jueces, como reconociera el ex presidente Branca en el encuentro de Parma de 1976. Tampoco es preciso traer a la memoria graves enfrentamientos con otro poder, como el muy conocido de ciertas sentencias constitucionales del Tribunal Supremo de los Estados Unidos con el presidente Roosevelt..., porque también las sentencias que no tienen inconveniente en torcer su argumentación jurídica hasta acabar coincidiendo complacientemente con el criterio de ese otro poder (recuérdese la aproximación de las sentencias alemanas de 15 de diciembre de 1970 y de 22 de mayo de 1975 a los aspectos más involucionistas de la política del Gobierno alemán) son, por razones obvias, sentencias con indirizzo politico. $\mathrm{Ni}$, en fin, es necesario considerar que ya el presidente Jefferson intentó obtener la destitución del juez Samuel Chase para así influir sobre la directriz política de las sentencias..., porque, más cerca de nosotros, está la oposición de la Democracia Cristiana italiana al nombramiento de Lelio Basso, conocida su orientación y su criterio sobre ciertas materias.

La sentencia constitucional, en definitiva - ese es su riesgo, pero pienso que también, en mayor medida, su riqueza y su virtud-, es a la vez realidad política y realidad jurídica fundidas en unidad de acto. Esa es su condición... Y lo único que cabe desear es que ese discurso formalizado que es la sentencia, conforme a lo que Francis Bacon consideraba que es el sentido de todo discurso, acierte a «aplicar la razón a la imaginación... para, de este modo, mover mejor la voluntad». 